\title{
Production of Liquid Hydrocarbons from Plastic Wastes
}

\author{
Zs. DoBó ${ }^{1}$, G. KECSMÁR ${ }^{2}$, Zs. JAKAB 3 , G. NAGY4 ${ }^{4}$, T. KoóS ${ }^{5}$ \\ 1University of Miskolc, Institute of Energy and Quality Affairs, zsolt.dobo@uni-miskolc.hu \\ 2University of Miskolc, Institute of Energy and Quality Affairs, kecsm.gerg@gmail.com \\ ${ }^{3}$ University of Miskolc, Institute of Energy and Quality Affairs, jzsofka94@gmail.com \\ ${ }^{4}$ University of Miskolc, Institute of Energy and Quality Affairs, nagy.gabii86@gmail.com \\ 5University of Miskolc, Institute of Energy and Quality Affairs, koos.tamas@uni-miskolc.hu
}

Abstract.Thermal pyrolysis of HDPE, LDPE, PP and PS plastic wastes were performed in a batch reactor and the yields of pyrolysis oils and liquid transportation fuels prepared by atmospheric distillation were determined. The gasoline fractions were tested in a traditional spark-ignition engine without any modifications or fuel blending. Fuel consumption and exhaust gas emission ( $\mathrm{NO}_{x}$, CO) were measured and compared to a commercial fuel (RON = 95). PS generated $70.5 \%$ gasoline range hydrocarbons from the solid waste, followed by PP with 42.1\%, LDPE with 40.8\% and HDPE with 37.3\%. The fuel consumption was reduced by $9.1-9.4 \%$ in the case of PS compared to reference measurement. Reduction in fuel consumption was noticeable at HDPE, LDPE and PP as well. PS gasoline decreased by 91-96\%, while HDPE, LDPE and PP more likely increased the CO emission of the engine compared to commercial gasoline. The results show that pyrolysis of plastic wastes is a promising method to generate value added liquid transportation fuels and reduce the footprint of waste accumulation in landfills.

\section{Introduction}

The global plastic waste generation reached 302 Mt in 2015, while the total plastic waste ever generated from primary plastics had reached 5800 Mt [1]. By projecting current global waste management trends to 2050, it is assumed that the primary plastic waste generated will be around 26,000 Mt [1]. $25 \mathrm{Mt}$ of plastic ended up in waste stream in the EU during the year of 2012 [2]. About $38 \%$ of this plastic waste was landfilled, $26 \%$ was recycled while $36 \%$ was utilized for energy recovery [2]. The amount of plastic waste slightly increased to $27.1 \mathrm{Mt}$ in 2016, while the landfilled amount dropped to $27.3 \%$, the recycled portion increased to $31.1 \%$ and the energy recovery also increased to $41.6 \%$ [3]. As the amount of plastic waste continuously increases, some alternative methods are being developed including pyrolysis, which is a promising method to generate value-added liquid fuel suitable for transportation as it can reduce the carbon footprint of the transportation industry and optimize waste management towards zero landfilling [4].

The pyrolytic products can be divided into a gas, liquid, and solid fraction. Based on the process parameters the gas/liquid ratio can be changed. The influencing factors of plastic waste pyrolysis were investigated by several researchers such as temperature [5,6], pressure [7,8], time [9], type of reactor $[2,10]$, catalyst $[11,12]$ and plastic waste material used [2]. The main goal of this research is to 
investigate the thermal pyrolysis of HDPE, LDPE, PP, PS plastic wastes and determine the yields of transportation fuels by performing atmospheric distillation of the pyrolysis oil. Additionally, the extracted gasoline fractions were tested in a traditional spark-ignition engine without any modifications or blending. Fuel consumption and exhaust gas emission $\left(\mathrm{NO}_{\mathrm{x}}, \mathrm{CO}\right)$ were measured and compared to a commercial fuel with RON $=95$.

\section{Materials and Methods}

The pyrolysis measurements were performed in a batch reactor $\left(2.25 \mathrm{dm}^{3}\right)$ equipped with electric resistance heating $(1 \mathrm{~kW})$ and a temperature controlled reflux to better control the cracking of molecules. The reflux was connected to a water-cooled heat exchanger in which the molecules with a boiling temperature higher than ambient were condensed. The liquid phase was collected in a product container, while the remaining gases were analyzed using gas chromatography and sent to a flare through a rotameter. The measurement system is shown in Fig. 1. The electric heater temperature was set to $700{ }^{\circ} \mathrm{C}$, which was determined by TG and DTG analysis of the waste plastic samples. The maximum temperature of vapors exiting the reflux was $200^{\circ} \mathrm{C}$.

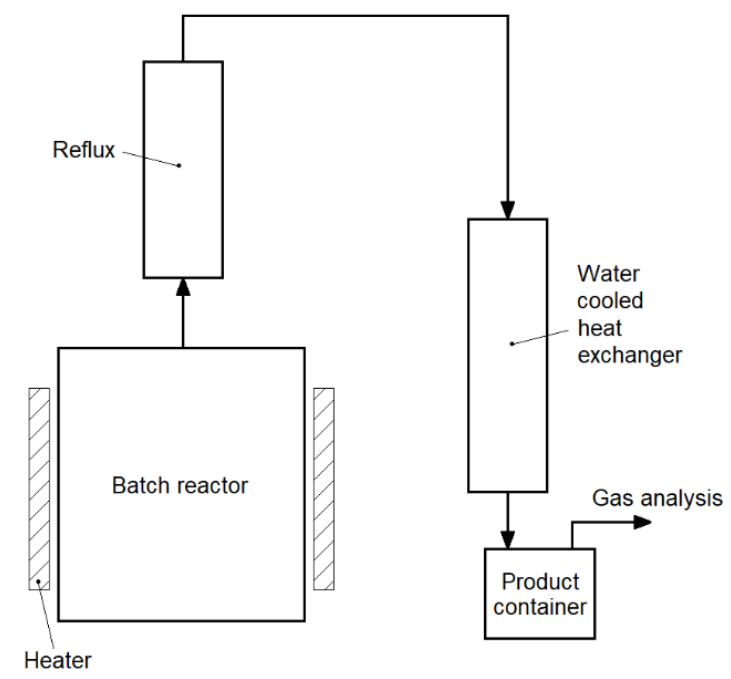

Figure 1. Schematic illustration of the measurement system.

The collected pyrolysis oils were processed by atmospheric distillation in a standard glass retort connected to a water-cooled condenser. The distillation cuts were $200{ }^{\circ} \mathrm{C}$ and $305{ }^{\circ} \mathrm{C}$. The $25-200{ }^{\circ} \mathrm{C}$ fractions (considered as gasoline) were tested in a traditional spark-ignition engine (Honda, GC-135) equipped with a carburetor. The $\mathrm{NO}_{\mathrm{x}}$ emissions were monitored by Horiba PG-250 type flue gas analyzer, while the $\mathrm{CO}$ was measured by gas chromatography (Dani Master).

\section{Results}

The mass distribution of the four plastic waste materials pyrolyzed in a batch reactor is summarized in Table 1. The PP produced the highest oil yield (83.4\%) and the lowest gas yield compared to the other materials used. Typically, the amount of solid residues was low (PS generated the highest char yield of 
4.6\%). The generated gas contains mostly $\mathrm{C}_{1}-\mathrm{C}_{3}$ hydrocarbons, but $\mathrm{CO}, \mathrm{CO}_{2}, \mathrm{H}_{2}$ and $\mathrm{C}_{3}+$ hydrocarbons are also present.

\begin{tabular}{|l|l|l|l|l|l|}
\hline & Unit & HDPE & LDPE & PP & PS \\
\hline Loaded plastic waste & $\mathrm{g}$ & 300 & 300 & 400 & 127 \\
\hline Char remained & $\%$ & 0.5 & 2.1 & 3.3 & 4.6 \\
\hline Pyrolysis oil & $\%$ & 73.9 & 58.8 & 83.4 & 79.2 \\
\hline Gas (by difference) & $\%$ & 25.6 & 39.1 & 13.3 & 16.2 \\
\hline
\end{tabular}

Table 1. Summary of mass distribution of different pyrolysis products.

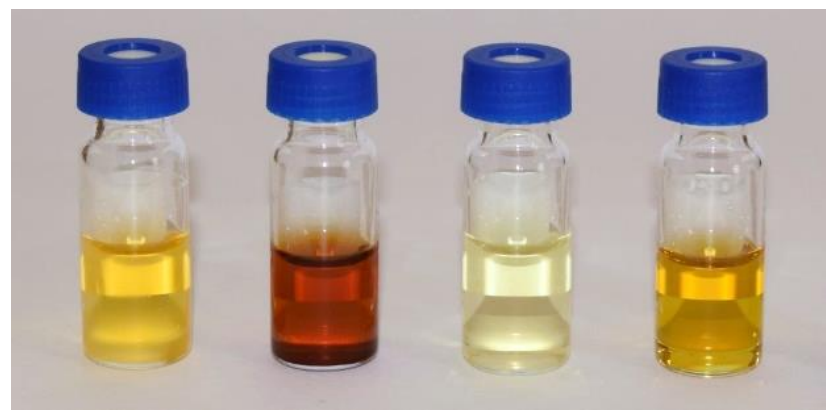

Figure 2. Pyrolysis oil samples obtained from the batch reactor equipped with temperature controlled reflux. From left to right: $H D P E, L D P E, P P, P S$.

As the pyrolysis oil contains a wide range of molecules, the oils were further processed by atmospheric distillation to separate the gasoline and diesel range hydrocarbons. The results of the atmospheric distillation are summarized in Table 2, where the yields are based on solid waste input. It can be clearly seen that the gasoline range hydrocarbons $\left(20-200{ }^{\circ} \mathrm{C}\right)$ are dominating, and the gasoline to diesel ratio in each case changes. While HDPE provided similar amounts of gasoline and diesel, PS pyrolysis gave almost gasoline range hydrocarbons.

\begin{tabular}{|l|l|l|l|l|}
\hline \multirow{2}{*}{$\begin{array}{l}\text { Temperature } \\
\text { range, }{ }^{\circ} \mathrm{C}\end{array}$} & \multicolumn{4}{|c|}{ Yield, $\mathrm{g} / \mathrm{kg}_{\text {waste }}$} \\
\cline { 2 - 5 } & HDPE & LDPE & PP & PS \\
\hline $20-200$ & 373 & 408 & 421 & 705 \\
\hline $200-305$ & 305 & 152 & 248 & 11 \\
\hline Total & 678 & 560 & 669 & 716 \\
\hline
\end{tabular}

Table 2. Transportation fuel yields from solid plastic waste.

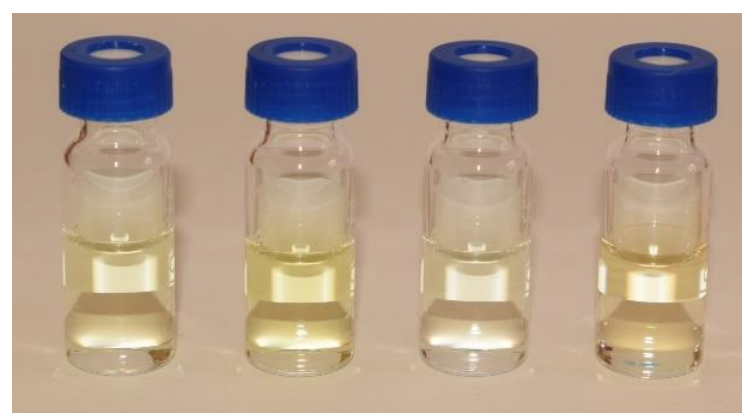

Figure 3. Photos of distillation products in $20-200^{\circ} \mathrm{C}$ range. From left to right: HDPE, LDPE, PP, PS. 


\subsection{Engine tests}

Engine tests were performed to investigate the fuel consumption and emissions and compare them to commercial gasoline with RON $=95$. The volumetric fuel consumption change in the case of HDPE, LDPE, PP and PS gasoline is shown in Fig. 4. It can be seen, that the fuel consumption was lower in each case compared to the reference measurement. PS showed the highest fuel consumption decrease with 9.1\% and 9.4\% at idling and under load, respectively. HDPE and LDPE also showed extreme fuel consumption reduction compared to the reference. Additionally, the overall operation of the engine with HDPE gasoline was smoother. A less significant change was observed during PP pyrolysis and the engine behaved similarly compared to the reference measurement.

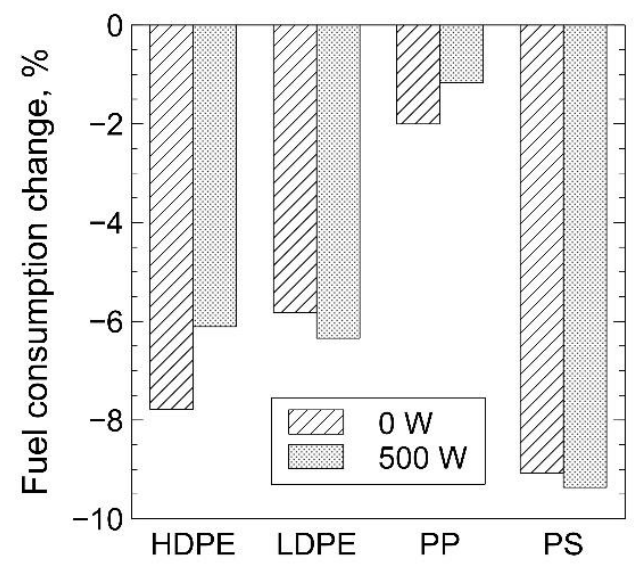

Figure 4. Fuel consumption change of the engine using various plastic gasoline compared to reference measurements. Typical fuel consumption of reference measurement when idling $(0 \mathrm{~W})$ and under load was $0.51 \mathrm{l} / \mathrm{h}$ and $0.61 \mathrm{l} / \mathrm{h}$, respectively.
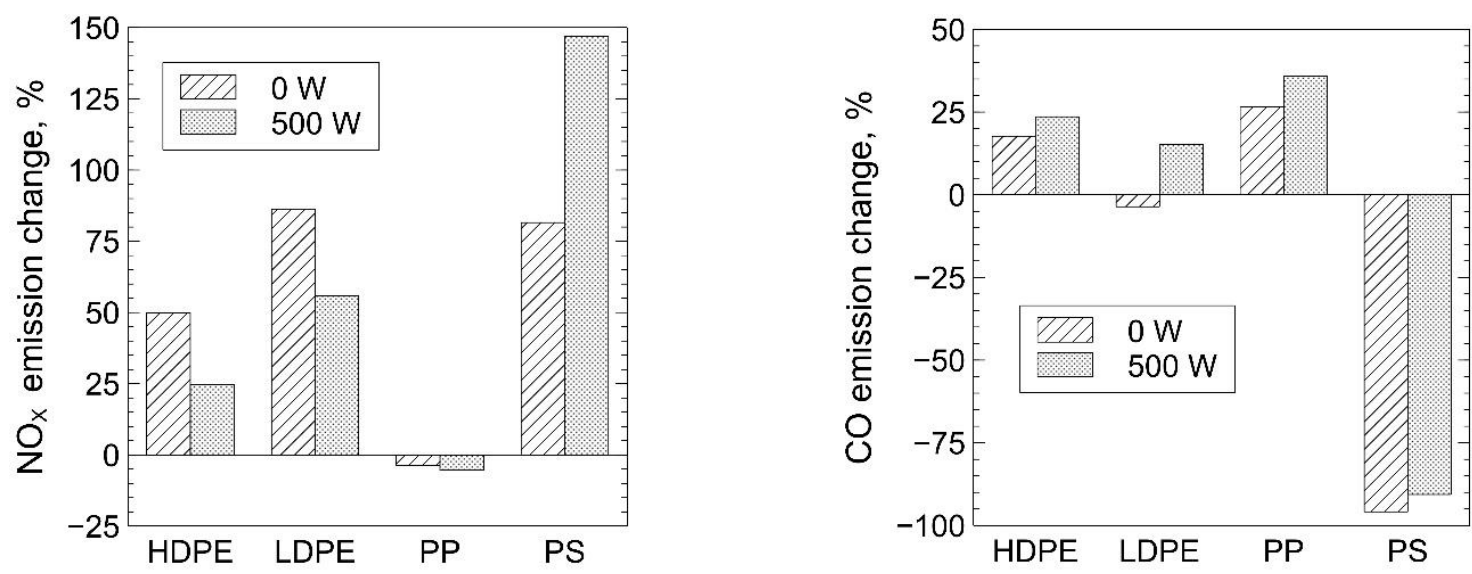

Figure 5. Left: $\mathrm{NO}_{\mathrm{x}}$ emission change of the engine using various plastic gasoline compared to reference measurements. Typical $\mathrm{NO}_{x}$ emission of reference measurement when idling $(0 \mathrm{~W})$ was 46.3 ppm and the $\mathrm{NO}_{\mathrm{x}}$ emission at $500 \mathrm{~W}$ electrical load was $77.9 \mathrm{ppm}$. Right: $\mathrm{CO}$ emission change of the engine using various plastic gasoline compared to reference measurements. Typical $\mathrm{CO}$ emission of reference measurement when idling $(0 \mathrm{~W})$ was $3.61 \mathrm{Vol} \%$ and the CO emission at $500 \mathrm{~W}$ electrical load was $2.78 \mathrm{Vol} \%$.

The $\mathrm{NO}_{\mathrm{x}}$ emission of the engine (Fig. 5 left) was higher in each case except PP, where a slight decrease was noticeable. While PS showed extreme low fuel consumption, its $\mathrm{NO}_{\mathrm{x}}$ emission was the highest 
(more than doubled under load conditions). As there was minor fuel consumption change at PP tests, a minor change is observed in terms of $\mathrm{NO}_{\mathrm{x}}$ emission as well. Consequently, both HDPE and LDPE generated a significantly higher amount of $\mathrm{NO}_{\mathrm{x}}$ as their fuel consumption was lower.

In terms of $\mathrm{CO}$ emissions (Fig. 5 right), PP gasoline generated the highest CO. Extreme low CO concentration was measured when PS gasoline was applied, the CO decreased $96 \%$ when idling and 91\% under load compared to the reference measurement. This indicates better combustion performance compared to the other fuels used in this study. HDPE and LDPE gasoline likely increased the CO emission except LDPE gasoline test under engine idling, where a slight decrease was observed. Overall, the CO emissions increased during HDPE, LDPE and PP tests, while PS significantly decreased the CO.

\section{Conclusion}

The product distribution during pyrolysis of HDPE, LDPE, PP and PS plastic wastes was determined and the pyrolysis oils were upgraded by atmospheric distillation to separate the transportation fuels. The gasoline yield was $37.3 \%, 40.8 \%, 42.1 \%$ and $70.5 \%$, while the diesel yield was $30.5 \%, 15.2 \%$, $24.8 \%$ and $1.1 \%$ for HDPE, LDPE, PP and PS, respectively. The neat gasoline fractions were tested in a traditional spark-ignition engine. Stable operation was observed during each gasoline fractions applied. The volumetric fuel consumption was lower by $9.1-9.4 \%$ when the PS gasoline was used compared to the reference measurement (commercial fuel, RON =95). HDPE gasoline reduced the fuel consumption by $6.1-7.8 \%$, LDPE by $5.6-6.3 \%$ and PP by $1.2-2.0 \%$. The highest $\mathrm{NO}_{\mathrm{x}}$ emission was measured during PS gasoline test when $82-147 \%$ more $\mathrm{NO}_{\mathrm{x}}$ was generated. On the other side, $\mathrm{CO}$ emission decreased by $91-96 \%$ when PS gasoline was fed. PP showed 3.7-5.4\% $\mathrm{NO}_{\mathrm{x}}$ reduction and this was the only case when the $\mathrm{NO}_{\mathrm{x}}$ concentration was lower. Although significantly lower $\mathrm{CO}$ emission was measured during PS gasoline test, HDPE, LDPE and PP gasoline likely generated more CO. The results show that the pyrolysis of different plastic wastes is a viable method to reduce the accumulation of plastics in landfills and provide value-added liquid transportation fuels.

\section{Acknowledgement}

The described article/presentation/study was carried out as part of the EFOP-3.6.1-16-2016-00011 "Younger and Renewing University - Innovative Knowledge City - institutional development of the University of Miskolc aiming at intelligent specialisation" project implemented in the framework of the Szechenyi 2020 program. The realization of this project is supported by the European Union, co-financed by the European Social Fund.

\section{References}

[1] R. Geyer, J.R. Jambeck, K.L. Law, Production, use, and fate of all plastics ever made, Science Advances 3 (2017) 1-5.

[2] S.D.A. Sharuddin, F. Abnisa, W.M.A.W. Daud, M.K. Aroua, A review on pyrolysis of plastic wastes, Energy Conversion and Management 115 (2016) 308-326. 
[3] Plastics - the facts 2018. An analysis of European plastics production, demand and waste data. https://www.plasticseurope.org/application/files/6315/4510/9658/Plastics_the_facts_2018_A F_web.pdf

[4] Gian Claudio Faussone, Transportation fuel from plastic: Two cases of study, Waste Management 73 (2017) 416-423.

[5] M. Sogancioglu, G. Ahmetli, E. Yel, A comparative study on waste plastics pyrolysis liquid products quantity and energy recovery potential, Energy Procedia 118 (2017) 221-226.

[6] A. López, I. de Marco, B.M. Caballero, M.F. Laresgoiti, A. Adrados, Influence of time and temperature on pyrolysis of plastic wastes in a semi-batch reactor, Chemical Engineering Journal 173 (2011) 62-71.

[7] K. Murata, K. Sato, Y. Sakata, Effect of pressure on thermal degradation of polyethylene, Journal of Analytical and Applied Pyrolysis 71 (2004) 569-589.

[8] R. Miranda, J. Yang, C. Roy, C. Vasile, Vacuum pyrolysis of commingled plastics containing PVC I. kinetic study, Polymer Degradation and Stability 72 (2001) 469-491.

[9] L.S. Diaz Silvarrey, A.N. Phan, Kinetic study of municipal plastic waste, International Journal of Hydrogen Energy 41 (2016) 16352-16364.

[10] E. Butler, G. Devlin, K. McDonnell, Waste polyolefins to liquid fuels via pyrolysis: review of commercial state-of-the-art and recent laboratory research, Waste and Biomass Valorization 2 (2011) 227-255.

[11] R. Miandad, M.A. Barakat, A.S. Aburiazaiza, M. Rehan, A.S. Nizami, Catalytic pyrolysis of plastic waste: a review, Process Safety and Environmental Protection 102 (2016) 822-838.

[12] R. Miandad, M.A. Barakat, M. Rehan, A.S. Aburiazaiza, I.M.I. Ismail, A.S. Nizami, Plastic waste to liquid oil through catalytic pyrolysis using natural and synthetic zeolite catalysts, Waste Management 69 (2017) 66-78. 